\title{
Long-term use of mandibular advancement splints for snoring and obstructive sleep apnoea: a questionnaire survey
}

\author{
A.D. McGown*, H.K. Makker*, J.M. Battagel", P.R. L'Estrange*, H.R. Grant", S.G. Spiro*
}

Long-term use of mandibular advancement splints for snoring and obstructive sleep apnoea: a questionnaire survey. A.D. McGown, H.K. Makker, J.M. Battagel, P.R.L'Estrange, H.R. Grant, S.G. Spiro. (C) ERS Journals Ltd 2001.

ABSTRACT: A mandibular advancement splint (MAS) may be an alternative treatment for snoring and obstructive sleep apnoea (OSA). However, there is little subjective or objective information concerning long-term effectiveness, compliance and side effects.

A retrospective questionnaire was used to survey these issues plus patient satisfaction and maintenance requirements in 166 patients who could have worn a mandibular advancement splint for over a year.

One-hundred and twenty-six $(76 \%)$ subjects returned the questionnaire, $(84$ with OSA, 42 snorers), of whom $69(55 \%)$ reported still using the splint regularly, $47(37 \%)$ every night. The most common reported reasons for stopping use were discomfort (29l $57 ; 52 \%$ of nonusers), and poor perceived efficacy (12 subjects). Users reported more daytime symptoms, and they and their partners were more likely to observe improvements with splint use. Side effects were reported by 49 subjects, more commonly in nonusers. Sixty-five of 67 current users and 23 of 41 nonusers reported less snoring with splint use $(p=<0.001)$.

Long-term mandibular advancement splint usage appeared less satisfactory than previously reported, however, splints were considered effective by $97 \%$ of current users and even by over half of those who had stopped use. Reasons for stopping use included side effects, social circumstances, dental treatment, as well as lack of perceived efficacy. Eur Respir J 2001; 17: 462-466.
*Dept of Thoracic Medicine, University College London Hospitals, ${ }^{\#}$ Dept of Orthodontics, Dental Institute, Royal London Hospital and Royal National Throat, Nose and Ear Division, Royal Free Hospitals Trust, London, UK.

Correspondence: A.D. McGown, Dept of Thoracic Medicine, Middlesex Hospital, Mortimer Street, London, WIN 8AA, UK.

Fax: 442076375809

Keywords: Long-term compliance mandibular advancement devices sleep apnoea syndromes

Received: April 212000

Accepted after revision August 122000
Snoring and obstructive sleep apnoea (OSA) may result from collapse of the upper airway during sleep because of loss of muscle tone and anatomical factors. Bringing the mandible forward advances the tongue and thus enlarges the retroglossal airway, reducing the tendency to collapse [1]. Mandibular advancement devices are therefore being increasingly used as a treatment for snoring and as a possible alternative to nasal continuous positive airway pressure (CPAP) devices in OSA. Several randomized controlled trials of mandibular advancement splints (MAS) or nasal CPAP have shown splints to be effective in some patients and although they do not always lower the apnoea-hypopnoea index (AHI) as satisfactorily as CPAP, they are preferred by most patients in shortterm trials of 4-12 weeks treatment [2-4]. One study of long-term use of CPAP over a median follow up of 22 months, showed that $20 \%$ of 1,103 people stopped treatment after taking a machine home [5]. However, follow up with MAS has been limited to much smaller numbers and for a shorter time, with few data on longterm usage [6]. As splints are usually fitted because a patient is symptomatic or their partner complains about their snoring, continued use of the device will depend on the patient and their partner's perceptions of symptomatic benefit and side effects. A retrospective questionnaire based study of factors affecting continued usage of mandibular advancement splints in 166 consecutive patients who had had a splint for at least one year was carried out.

\section{Methods}

One-hundred and sixty-six patients (140 males, 26 females) with sleep disordered breathing (111 OSA, 55 snorers) who were fitted with an MAS between 1994 and March 1997, i.e. $\geqslant 1$ yr prior to the study, were sent a questionnaire which asked about long-term effectiveness, compliance and side effects. These were consecutive patients sent for the fitting of an MAS and comprised two groups: group A (70 people: 58 OSA, 12 simple snorers) were diagnosed and fitted with MAS at the Middlesex Hospital, London and group B (96 people: 53 OSA, 43 simple snorers) were diagnosed at the Royal National Throat, Nose and Ear Hospital, London and fitted with MAS at the Royal London Hospital. All subjects had undergone a sleep study to define their sleep disordered breathing. OSA was defined by an AHI > 10 with daytime symptoms, and 
$40 \%$ of the patients with OSA had an AHI $>30$. Group A were fitted with a modified adjustable Silensor mandibular advancement splint and group $\mathrm{B}$ with a removable Herbst device. Both comprise upper and lower elements with lateral connectors, allowing mouth breathing and a degree of mouth opening. The Silensor device allows mouth opening without loss of mandibular advancement, using variable length plastic connectors; whereas with the stainless steel Herbst piston and tube attachment, opening is associated with a backwards hingeing of the lower jaw. Each device was fitted and adjusted by one specialist dentist at each centre. In both centres further adjustment was carried out as necessary and patients could make appointments or send in their devices for repair or replacement.

The mandibular advancement questionnaire was based on one previously used for assessment of compliance and factors influencing acceptance of CPAP, and requested subjects to record the presence or absence of specific symptoms before and after treatment [7]. The questionnaire used in the present study aimed to assess usage, as declared by each individual, as well as effectiveness, side effects and maintenance requirements. Questionnaires were posted to all subjects and self-administered. A second and third mailing was sent to nonresponders and attempts were also made to contact these individuals by phone. Ethical approval was by chairman's action for the relevant ethics committee.

Initially Group A and Group B were analysed separately and then together. Chi-squared tests of independence were used to compare categorical variables in the replies of patients who were current users of the splint with those who had stopped using the splint. Mantel-Haenszel tests of heterogeneity were performed by group on the combined group and if nonsignificant, adjusted $p$-values and odds ratios for the whole group were quoted. For continuous variables t-tests were used. The statistical package used was Stata (Stata Corporation, TX, USA).

\section{Results}

\section{Response rate}

A total of $126 / 166$ patients $(76 \%)$ responded to the questionnaire (Group A 55/70 (78\%), Group B 71/96 $(74 \%))$. One-hundred and fifteen answered most of the questions and 11 just gave their reason for stopping MAS use. The responding group consisted of 84 patients with OSA and 42 snorers, and did not differ from the whole group in diagnostic composition. An attempt was made to contact the 40 nonresponders by telephone; 34 could not be contacted, 14 of whom had moved house and one had died. The remaining six were contacted; of these three were using CPAP whilst three were still using MAS.

\section{Reported usage}

Sixty-nine out of 126 responders $(55 \%)$ reported using the splint regularly, at least once a week. Of these,

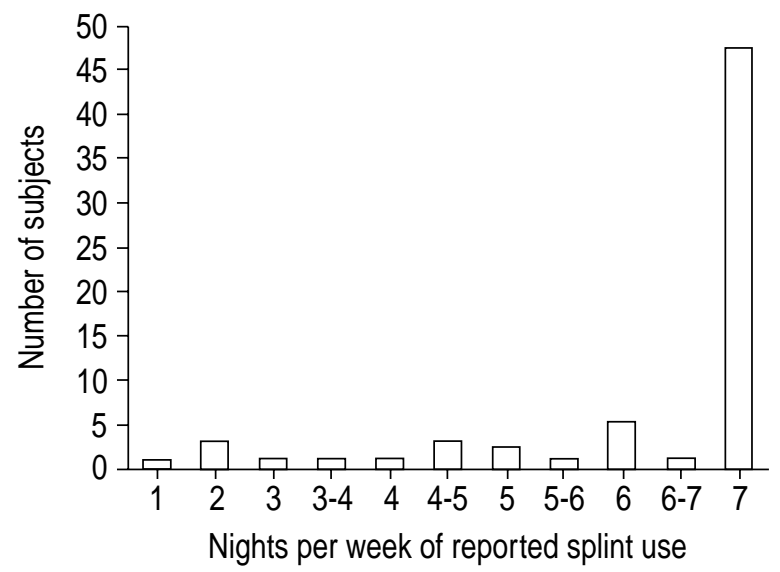

Fig. 1. - Reported compliance in nights per week of splint use in 66 continued users.

47 subjects (68\%) reported wearing the splint every night (fig. 1). The 69 current users, who had all been fitted with their MAS $>1 \mathrm{yr}$, previously, reported having used the splint for a mean duration of 21.5 months (median (range) $22(5-44)$ months). They reported using the splint on average $6.6 \mathrm{~h} \cdot$ night $^{-1}$ (range $3-8.5)$, and $42(4-63) \mathrm{h}$ a week. The difference in reported continued usage between snorers and those with OSA $(18 / 42,43 \%$ versus $51 / 84,61 \%)$ was not significant $(\mathrm{p}<0.1)$. Of the 56 people who had stopped using the splint, the most common reason given for stopping was discomfort in $29(52 \%)$, followed by lack of effectiveness in $12(21 \%)$ (table 1$)$. There was no significant difference in age or sex between users and those who had stopped, and there was no significant difference in reported use between Groups A and B.

\section{Symptoms}

The distribution of pre- and postsplint symptoms and side effects in relation to continued use were similar in Groups A and B, and the data are presented for the combined group.

\section{Presplint symptoms}

Users reported more daytime symptoms typical of sleep disordered breathing when compared to nonusers

Table 1. - Reasons given for stopping use

\begin{tabular}{lr}
\hline Reason & $\mathrm{n}(\%)$ \\
\hline Discomfort & $29(52)$ \\
Ineffective & $12(21)$ \\
Now using CPAP & $8(14)$ \\
Miscellaneous & $8(14)$ \\
Broken device & $6(11)$ \\
Dental treatment & $6(11)$ \\
Successful ENT operation & $6(11)$ \\
Would not stay in place & $5(9)$ \\
\hline
\end{tabular}

Total number $=56$. CPAP: continuous positive airway pressure; ENT: Ear, nose and throat. 
$(1.97+/-0.19$ versus $1.29+/-0.22, \mathrm{p}=0.025)$. However, the average number of night-time symptoms was similar for users and nonusers $(2.59+/-0.16$ versus $2.45+/-0.19, \mathrm{NS})$.

\section{Post-splint changes}

Users and their partners reported improvements in daytime somnolence, snoring, headache and coping ability significantly more often than nonusers. Less headache remained significant even after correcting for diagnosis of OSA, unlike the other two daytime improvements. Lack of any improvement noticed either by the patient or by their partner was associated with stopping use. Ninety-three per cent of users and $39 \%$ of nonusers estimated an improvement in snoring of $\geqslant 50 \%$. Sixty-four per cent of users and $33 \%$ of nonusers estimated an improvement in daytime symptoms of $\geqslant 50 \%$. There was an improvement in reported witnessed apnoea for all responders (table 2).

\section{Side effects}

Both current users and nonusers reported side effects of discomfort (25/69 users, 24/37 nonusers), temporomandibular joint pain (26/69 users, 21/37 nonusers), sleep disturbance (12/69 users, 12/37 nonusers), excessive salivation (7/69 users, 13/37 nonusers) and altered bite (9/69 users, 2/37 nonusers). Side effects occurred every night according to $41 \%$ of users and $57 \%$ of those who had stopped. Subjects who had stopped use also reported a higher average number of side effects than users $(2.03+/-0.19$ versus $1.29+/-0.13 \mathrm{p}=0.001)$.

\section{Factors associated with continued usage}

Table 3 shows odds ratios relating nonusers to users for symptoms and side effects where there was a significant difference between the two groups. The strongest associations were between reported snoring reduction and continued use and between lack of improvement according to the partner and stopping splint use.

Table 2. - Comparison of witnessed apnoea reported preand postsplint use in all responders (63 users, 24 nonusers)

\begin{tabular}{lccccc}
\hline & & \multicolumn{4}{c}{ Apnoea post } \\
\cline { 3 - 6 } & & never & sometimes & often & total \\
\hline \multirow{2}{*}{ Apnoea pre } & never & 25 & 0 & 0 & 25 \\
& sometimes & 20 & 10 & 0 & 30 \\
& often & 15 & 17 & 0 & 32 \\
& total & 60 & 27 & 0 & 87 \\
\hline
\end{tabular}

$\mathrm{p}<0.001$ for the difference in witnessed apnoea pre- and postsplint use.

\section{Maintenance and replacement}

Splints needed replacement in 30 of 65 users $(46 \%)$ and 15 of 32 nonusers (47\%). Breakages were common, reported in 40 of 85 people (with no difference between users and nonusers). Users reported having made an average of 1.75 contacts to their specialist dentist in the first 6 months after splint insertion $(1(0-6))$ and nonusers 2.27 (2 (0-9)). The Middlesex Hospital group had more breakages and visits reported than the Royal London Hospital group; this may be partly explained by the different splint models (the plastic connectors on the Silensor splints break off relatively frequently but are easy and cheap to replace).

\section{Preference}

Of the 41 patients who had tried both CPAP and the MAS, $8(19.5 \%)$ preferred CPAP, 29 (71\%) preferred the splint and $4(10 \%)$ were unsure.

\section{Discussion}

This study is the first to survey long-term experience of MAS in a reasonably large number of patients. The overall reported continued usage was quite low at $55 \%$, with only 47 of the 126 subjects claiming use each night. Several reasons were given for stopping, with discomfort the most common. Side effects were frequent, but less than in other studies $[8,9]$. As expected, patients whose snoring and symptoms subjectively improved were more likely to report using the splint, and where the patient or especially the partner noticed no change (i.e. no improvement in snoring) they tended to stop. Patients with daytime symptoms were also more likely to report continued use than those without.

This study is limited by being questionnaire-based and retrospective, without objective evidence of efficacy or compliance. Herbst devices have been shown to be effective in a randomized controlled trial against CPAP in OSA [2] as has the splint used in the Middlesex group [10].

Assessing the effectiveness of a treatment for snoring by questionnaire although widely used should be replaced by objective measurements, but a method still needs to be developed to assess MAS compliance directly. Other studies have found differences between subjective and objective measurements of snoring, for example post uvulopalatopharyngoplasty where subjective improvement without objective alteration in snoring index was noted [11]. Furthermore, where objective improvements are noted, the correlation with subjective measures may be weak [12]. Comparisons are complicated by the fact that home and hospital studies give different results [13] and that characteristics of the snore other than snoring index may correlate with subjective improvement, e.g. in patients following laser assisted uvuloplasty [14]. STRADLING et al. [15] measured snoring objectively at home in 15 patients using MAS who all claimed a subjective $>50 \%$ improvement in snoring, and showed a clear and consistent improvement in snoring measured as snores per hour (median 
Table 3. - Factors associated with stopping use or continued use. Odds ratios (OR) compare nonusers to users adjusting for group.

\begin{tabular}{lrr}
\hline Symptom/side effect & OR $(95 \%$ CI) & p-value \\
\hline Stopping use & & $<0.001$ \\
No change noticed by partner & $19.0(4.23-85.5)$ & 0.002 \\
No improvement noticed by patient & $4.68(1.69-13.0)$ & 0.002 \\
Excessive salivation & $4.68(1.68-13.0)$ & 0.005 \\
Discomfort & $3.19(1.39-7.31)$ & 0.036 \\
No presplint daytime symptoms & $2.55(1.05-6.17)$ & 0.009 \\
Continued use & & $<0.001$ \\
Less headache using the splint & $0.053(0.012-0.236)$ & 0.008 \\
Less snoring using the splint & $0.297(0.119-0.738)$ & 0.031 \\
Presplint daytime dozing off & $0.308(0.104-0.917)$ & 0.030 \\
Coping better using the splint & $0.316(0.110-0.908)$ & 0.050 \\
Presplint inability to concentrate & $0.320(0.099-1.03)$ & 0.026 \\
Presplint headaches & $0.352(0.139-0.892)$ & \\
More awake using the splint & & \\
\hline
\end{tabular}

95\% CI: 95\% confidence interval. ${ }^{\#}$ : none of the subjects reporting less headache with the splint were nonusers, hence the odds ratio of 0 .

193 versus 20 snores per hour, $\mathrm{p}<0.0001$ ) or time spent snoring (818 versus $50 \mathrm{~s}, \mathrm{p}<0.0002)$. This is the only study directly comparing objective and subjective measures of snoring with MAS, although two other studies have demonstrated objective snoring reduction $[8,16]$. There is therefore some justification for the assumption that the $93 \%$ of our current users who claimed a $50 \%$ improvement in snoring or more were probably improved.

Compliance with treatment of chronic conditions is known to be poor. With CPAP, subjective compliance is greater than objective compliance; in one study of 62 patients, the two differed by $\sim 1 \mathrm{~h}$ per night, but there was a correlation between subjective and objective compliance data $(r=0.68, p<0.0001)$ [17]. In nontrial settings with standard follow-up, CPAP compliance may be considerably worse [18]. Previous findings of long-term reported compliance with MAS range from $52 \%$ of 23 subjects at 3 yrs [19]; to $75 \%$ of 68 patients after a mean of 7 months (range $2-25$ months) [9]; to $79 \%$ of 57 subjects at 3.5 months (range 1-9) [8]. Reasons for noncompliance included lack of efficacy, temporomandibular joint pain and other side effects $[19,9]$. Compliers were said to use the device "for the entire night and almost every night" [9]. The group of current users in the present study claimed to average $6.6 \mathrm{~h}$ per night and $42 \mathrm{~h} \cdot$ week $^{-1}$; comparable to the $5.8 \mathrm{~h} \cdot$ night $^{-1}$ of self-reported compliance in 204 patients wearing CPAP [17].

Eighty out of 94 patients reported an improvement in snoring, compared to 64 of 65 in another study [9]. Some improvement was reported by 16 of 29 subjects no longer using the splint, and by 16 of their 28 partners. HofFSTEIN et al. [7], using the original questionnaire for the study in patients wearing CPAP, found that beneficial changes were noted in $47 \%$ of the noncompliant group, both by the patients themselves and by their families. These results show that with both the MAS and with CPAP, some people are noncompliant despite subjective effectiveness. The finding, that the presence of presplint daytime symptoms was important for continued use is also seen in patients using CPAP. MCARDLE et al. [5] found that
AHI and Epworth Sleepiness Scale independently predicted CPAP compliance in 1,103 patients. This tendency for patients without daytime symptoms to be less compliant, suggests that simple snorers may be less compliant than patients with OSA (although this difference was nonsignificant in the present study). When snorers and patients with OSA were analysed separately, snorers who dozed off during the day were more likely to report current usage $(\mathrm{p}<0.05)$, and the presence of daytime symptoms no longer predicted usage in patients with OSA. The finding of reported improvement in headache with the splint with continued use has been noted previously [16]. This effect is seen in snorers as well as subjects with OSA and so may be due to an effect on bruxism or alteration in the atlanto-occipital alignment [20].

Splints may become fully effective only after one or more further adjustments and both dental specialists only performed adjustment following patient contact. It is unlikely that routine adjustments would improve usage, as the noncompliant patients made a similar number of contacts in the first 6 months $(2.27$ versus 1.75). Splint breakages were as common in the current users as in those who had stopped using despite the different duration of use, and were among the reasons cited for stopping use. There is no information on splint maintenance and adjustment, and the questionnaire data, although limited in value by recall bias, suggest that these factors should be taken into account when looking at cost effectiveness of MAS.

To conclude, about half of patients issued with mandibular advancement splints will report still using them at a median follow up of 22 months. Use is dependent on social circumstances as much as physical symptoms, especially at the milder end of the clinical spectrum where daytime symptoms are absent. In more severe cases where the patient has daytime symptoms and the alternative is nasal continuous positive airway pressure, splints are the preferred option if effective and reported usage is higher. There remains a need for prospective objective data on mandibular advancement splints compliance, maintenance and breakages so that an accurate cost-effectiveness analysis can be made. 
Acknowledgements. The authors would like to thank C. Croft and B. Kotecha from the Royal National Throat, Nose and Ear Hospital and A. Simonds from Brompton Hospital, for allowing them to approach their patients. They would also like to thank G. Leonardi, London School of Hygiene and Tropical Medicine, for statistical advice.

\section{References}

1. Ryan CF, Love LL, Peat D, Fleetham JA, Lowe AA. Mandibular advancement oral appliance therapy for obstructive sleep apnoea: effect on awake calibre of the velopharynx. Thorax 1999; 54: $972-977$.

2. Clark GT, Blumenfield I, Yoffe N, Peled E, Lavie P. A crossover study comparing the efficacy of CPAP with anterior mandibular positioning devices on patients with obstructive sleep apnoea. Chest 1996; 109: 1477 1483.

3. Ferguson KA, Ono T, Lowe AA, Keenan SP, Fleetham JA. A randomised crossover study of an oral appliance vs nasal-continuous positive airway pressure in the treatment of mild-moderate obstructive sleep apnoea. Chest 1996; 109: 1269-1275.

4. Ferguson KA, Ono T, Lowe AA, Al-majed S, Love LL, Fleetham JA. A short term controlled trial of an adjustable oral appliance for the treatment of mild to moderate obstructive sleep apnoea. Thorax 1997; 52: $362-368$.

5. McArdle N, Devereux G, Heidarnejad H, Engleman HM, Mackay TW, Douglas NJ. Long-term use of CPAP therapy for sleep apnoeal/hypopnoea syndrome. Am J Respir Crit Care Med 1999; 159: $1108-1114$.

6. Schmidt-Nowara WW, Lowe A, Wiegand L, Cartwright R, Perez-Guerra F, Menn S. Oral appliances for the treatment of snoring and obstructive sleep apnoea: a review. Sleep 1995; 18: $501-510$

7. Hoffstein V, Viner S, Mateika S, Conway J. Treatment of obstructive sleep apnoea with nasal continuous positive airway pressure. Patient compliance, perception of benefits, and side effects. Am Rev Respir Dis 1992; 145: 841-845.

8. O'Sullivan RA, Hillman DR, Mateljan R, Pantin C, Finucane KE. Mandibular advancement splint: an appliance to treat snoring and obstructive sleep apnoea. Am J Respir Crit Care Med 1995; 151: $194-198$.

9. Schmidt-Nowara WW, Meade TE, Hays MB. Treatment of snoring and obstructive sleep apnoea with a dental orthosis. Chest 1991; 99: $1378-1385$.

10. Tan YK, L'Estrange PR, Smith C, Grant HR, Simonds AK, Spiro SG. A randomised crossover study of continuous positive airway pressure vs mandibular advancement splint in mild and moderate obstructive sleep apnoea. Eur Respir $J$ 1998; 12: Suppl. 28, 5s.

11. Miljeteig H, Mateika S, Haight JS, Cole P, Hoffstein V. Subjective and objective assessment of uvulopalatopharyngoplasty for treatment of snoring and obstructive sleep apnoea. Am J Respir Crit Care Med 1994; 150: $1286-1290$.

12. Smithson AJ, White JE, Griffths CJ, et al. Comparison of methods for assessing snoring. Clin Otolaryngol 1995; 20: $443-447$.

13. Osman EZ, Osborne J, Hill PD, Lee BW. Snoring assessment: do home studies and hospital studies give different results? Clin Otolaryngol 1998; 23: 524-527.

14. Walker RP, Gatti WM, Poirier N, Davis JS. Objective assessment of snoring before and after laser-assisted uvulopalatoplasty. Laryngoscope 1996; 106: $1372-$ 1377.

15. Stradling JR, Negus TW, Smith D, Langford B. Mandibular advancement devices for the control of snoring. Eur Respir J 1998; 11: $447-450$.

16. Tegelberg A, Wilhelmsson B, Walker-Engstrom ML, et al. Effects and adverse events of a dental appliance for treatment of obstructive sleep apnoea. Swed Den J 1999; 23: 117-126.

17. Engleman HM, Asgari-Jirhandeh N, McLeod AL, Ramsey CF, Deary IJ, Douglas NJ. Self-reported use of CPAP and benefits of CPAP therapy. A patient survey. Chest 1996; 109: 1470-1476.

18. Hoy CJ, Vennelle M, Kingshott RN, Engleman HM, Douglas NJ. Can intensive support improve continuous positive airway pressure use in patients with the sleep apnea hypopnea syndrome? Am J Respir Crit Care Med 1999; 159: 1096-1100.

19. Clark GT, Arand D, Chung E, Tong D. Effect of anterior mandibular positioning on obstructive sleep apnoea. Am Rev Respir Dis 1993; 147: 624-629.

20. Klineberg I. Craniomandibular disorders and orofacial pain - diagnosis and management. Oxford, Butterworth-Heinemann, 1991. 